\title{
Use of weather generators to assess impact of climate change: thermal actions on structures
}

\author{
Pietro Croce, Flippo Landi, Paolo Formichi, Roberto Castelluccio
}

\begin{abstract}
As consequence of global warming extreme weather events might become more frequent and severe across the globe. The evaluation of the impact of climate change on extremes is then a crucial issue for the resilience of infrastructures and buildings and is a key challenge for adaptation planning. In order to assess changes in extreme maximum and minimum air temperatures, Regional Climate Models outputs and observed data series have been analyzed and a new technique for the assessment of climate model uncertainty has been developed. Considering different radiation scenarios, some results are presented for the Italian Mediterranean region proving the ability of the method to define factors of change for climate extremes as well as to assess their evolution in time, allowing at the same time to estimate the uncertainty range of the model. Extending the analysis to different climate models it will be possible to take into account in climate change impact study also model uncertainty in response to same radiative forcing.
\end{abstract}

Keywords - climate change, thermal actions, Eurocodes, extreme value, climate model, weather generator

\section{Introduction}

In the mid-term future, climate change could determine significant alterations of climatic actions, so impacting the design of new structures and the reliability of existing, ones designed in accordance with present or past Codes [1].

Climatic actions on structures are currently based on extreme value analysis applied to past observations of the underlying natural phenomena, under the assumption of stationary climate conditions [2]. In design context, climate is considered as a stationary stochastic process varying in a neighbourhood of an unchanging mean state, and stationary return level and no changes in the frequency of extremes are usually assumed. Since changing climate makes this assumption questionable, alterations of frequency and intensity of extremes events as well as variations of statistical properties of extremes may be expected over time [3].

The aim of the paper is then to study the influence of climate change on thermal actions on structures, providing guidance for potential amendments of the current version of minimum and maximum shade air temperature maps.

This purpose is particularly motivated in view of the evolution of the structural Eurocodes that will lead to the

Pietro Croce, Flippo Landi, Paolo Formichi, Roberto Castelluccio University of Pisa, Department of Civil and Industrial Engineering Structural Division Italy adoption of the second generation of Eurocodes in 2020 as requested in the Mandate M/515 of the European Commission [4] to CEN (European Committee for Standardization) [5].

In this work, Regional Climate Model (RCM) outputs have been analysed to estimate future trends in extreme temperatures, and in order to take into account the uncertainty in the model related to the internal climate variability, which can bear significant implications for interpreting regional to local changes especially at smaller spatial scales [6], a new weather generator has been developed.

\section{Climate Projections for Impact Studies}

Information about future climate and its change is usually inferred from General Circulation Models (GCMs) and at a smaller resolution from Regional Climate Models (RCMs). Regional Climate Models (RCMs) are applied over a limited-area domain with boundary conditions derived from global reanalyses or global climate model output [7].

They accounts for the sub-GCM grid scale forcing (e.g. complex topographical features and land cover heterogeneities) in a physically-based way and enhance the simulation of atmospheric circulations and climatic variables at fine spatial scales. However, RCMs inherits the biases and other deficiencies of the GCMs, and even at highest resolution remains a gap between the scale of RCM predictions and applications at the local scale.

One of the most challenging problems in assessment studies of impacts of climate change is then to bridge this gap and recently, a considerable effort has been made on the development of downscaling techniques for GCMs and RCMs. A comprehensive review on the subject can be found in [8].

In this paper, these relevant issues have been investigated in order to set up a suitable procedure for the definition of future trends of climatic actions at local scale starting from the output of RCMs and taking into account the uncertainty in the model itself. In particular, the use of weather generators has been considered to identify factor of changes for climatic actions and their uncertainty range.

In the next paragraphs, an original method to generate consistent climate data series from the output of climate models is presented and the methodology for the analysis of extreme temperatures is described.

\section{Study Area and Dataset}

Daily climate projection of maximum and minimum temperature $\left(\mathrm{T}_{\max } ; \mathrm{T}_{\min }\right)$ developed within the EUROCORDEX initiative [9] are analysed for the control period 
1951-2005 (Historical Experiment), where "run" is forced by observed atmospheric composition changes and for the future period 2006-2100 (RCPs Experiment), where "run" is forced by different RCPs scenarios [10]. In particular, data provided by the Danish Meteorological Institute (DMI) have been investigated for the so-called 'Historical Experiment', the 'RCP4.5 Experiment' and the 'RCP8.5 Experiment' (model specifications are reported in Table I)

TABLE I. OVERVIEW ON THE ANALYZED CLIMATE PROJECTIONS AND THEIR MAIN CHARACTERISTICS

\begin{tabular}{|c|c|c|c|c|c|c|}
\hline institute_id & $\begin{array}{c}\text { RCM } \\
\text { name }\end{array}$ & Resolution & $\begin{array}{c}\text { driving_ } \\
\text { model_id }\end{array}$ & $\begin{array}{c}\text { driving__ } \\
\text { experiment }\end{array}$ & $\begin{array}{c}\text { driving_ } \\
\text { ensemble }\end{array}$ & Period \\
\hline DMI & HIRHAM5 & $0.11 \mathrm{deg}$ & EC-EARTH & historical & r3i1p1 & $1950-2005$ \\
\hline DMI & HIRHAM5 & $0.11 \mathrm{deg}$ & EC-EARTH & rcp45 & r3i1p1 & $2006-2100$ \\
\hline DMI & HIRHAM5 & $0.11 \mathrm{deg}$ & EC-EARTH & rcp85 & r3i1p1 & $2006-2100$ \\
\hline
\end{tabular}

The geographical area considered in the study comprises the Zones 3-4 of the Italian Mediterranean climatic region defined by the EN1991-1-3. These zones are illustrated in Figure1, together with the grid points at which observed climate data are provided by the E-OBS gridded dataset [11] $\left(0.22^{\circ}\right.$ grid resolution $\left.\sim 25 \mathrm{~km}\right)$ and the grid points at which climate projections are provided (EUR-11 grid).

Since the grid-cell by grid-cell comparison between climate projections and observed data requires a remapping of the EURO-CORDEX output over the EOBS grid, a conservative projection of daily climate data has been carried out according the procedure proposed in [12]. Considering that four EUR-11 grid cells exactly fit into one E-OBS cell, the conservative projection results in a simple arithmetic four-point average on the finer grid.

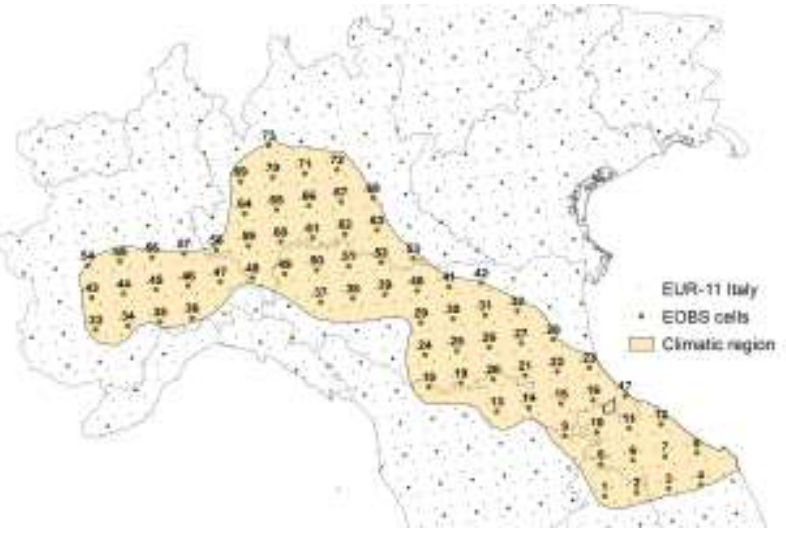

Figure 1. E-OBS grid cells in Zone 3-4 of the Italian Mediterranean climatic region defined by EN1991-1-3.

\section{Methodology}

\section{A. Definition of Weather Generator}

Weather generators are currently used as statistical downscaling technique in climate change impact studies [8][13][14]. They are statistical models based on regression relations between daily climatic variables, which are able to generate time-series of climatic variables with statistical properties similar to the input ones.

In climate changes studies, they are applied to generate future weather series from the observed climate statistics factored by a factor of change derived from the analysis of climate model output.

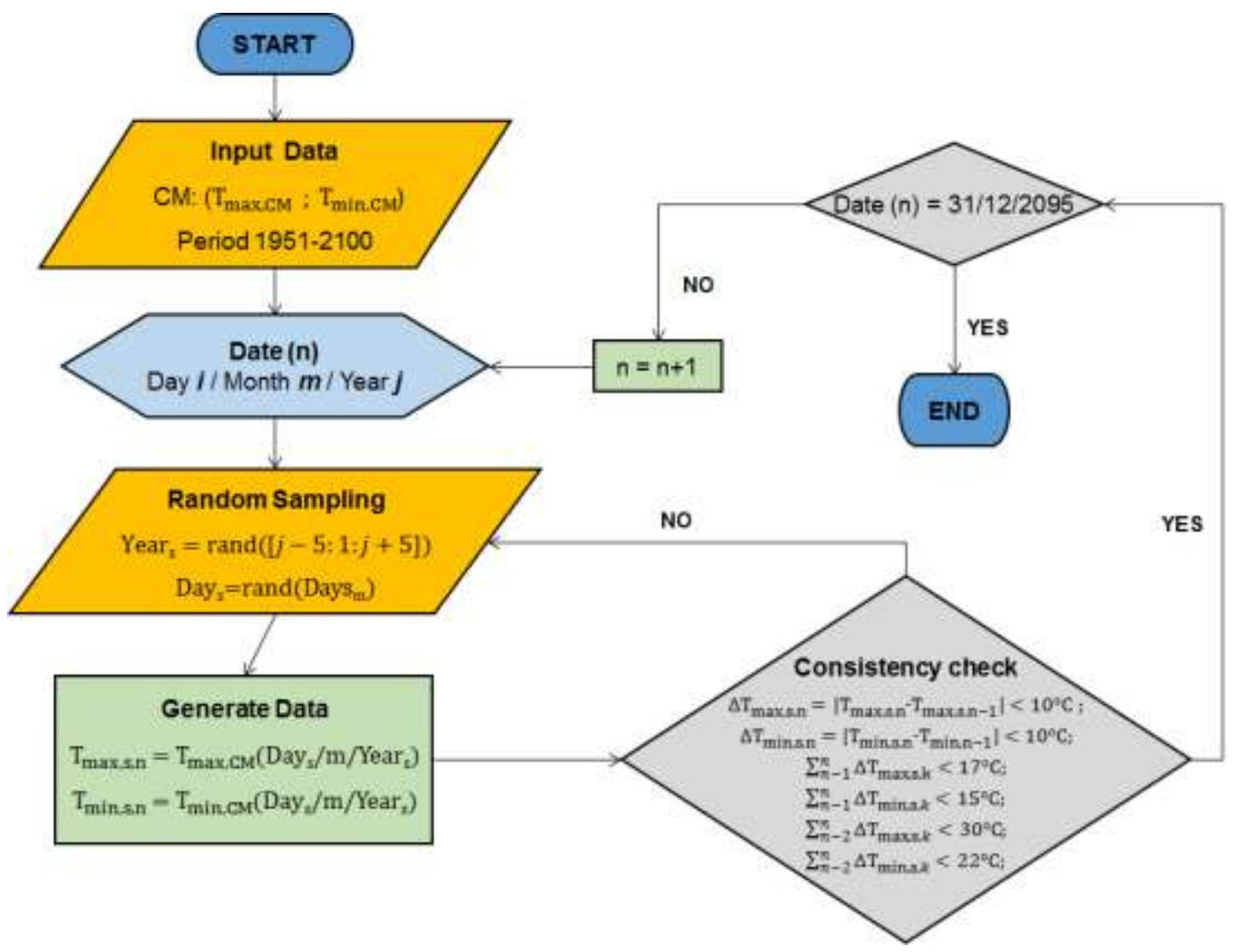

Figure 2. Flow chart of the algorithm for the generation of climate data series. 
This method assumes that the climate model represents better the change in the statistical properties of the climate variable from the present to the future climate, rather than the absolute values of the variables.

In our approach, instead of generating weather series from the statistics of the climate variables, climate data series are generated directly by sampling from the climate model outputs according the following procedure, summarized in the flowchart illustrated in Fig. 2:

- daily data for Day $i$ at Month $m$ in Year $\mathrm{j}\left(T_{\max , s, n}\right.$; $\left.T_{\min , s, n}\right)$ are random sampled from the daily data of the climate variables at the same month $m$ in the period defined by the considered year plus and minus five years $[j-5 ; j+5]$. This time window of eleven years for the sampling interval has been considered short enough to avoid potential influences of the climate change on the climate variables.

- the random sampling procedure is implemented with some physical constraints in order to avoid the generation of unrealistic weather data series. In particular, the following constraints for maximum and minimum temperatures in two, three and five consecutive days have been defined from the analysis of the actual data for each Day $i$

$$
\begin{gathered}
\Delta T_{\max , s, n}=\left|T_{\max , s, n}-T_{\max , s, n-1}\right|<10^{\circ} \mathrm{C}, \\
\Delta T_{\min , s, n}=\left|T_{\min , s, n}-T_{\min , s, n-1}\right|<10^{\circ} \mathrm{C}, \\
\sum_{n-1}^{n} \Delta T_{\max , s, k}<17^{\circ} C ; \sum_{n-1}^{n} \Delta T_{\min , s, k}<15^{\circ} \mathrm{C}, \\
\sum_{n-3}^{n} \Delta T_{\max , s, k}<30^{\circ} \mathrm{C} ; \sum_{n-3}^{n} \Delta T_{\min , s, k}<22^{\circ} \mathrm{C} .
\end{gathered}
$$

In this way, consistent climate data series of daily maximum and minimum air temperature $\left(T_{\max , s} ; T_{\min , s}\right)$ are generated for the considered climate model in the period 1956-2095. Once generated these series, an extreme value analysis can be performed for each series, aiming to identify future trends in characteristic values and their uncertainty range.

\section{B. Extreme Value Analysis and Factor of Changes for $T_{\text {max }}$ and $T_{\text {min }}$}

Each climate data series of daily maximum and minimum air temperature $\left(T_{\max , s} ; T_{\min , s}\right)$ have been analysed according different time windows for a correct definition of non-stationary extremes suitable for structural design [2].In particular, the maxima data series have been divided in appropriate time windows of forty year long and for each time window an extreme value analysis has been carried out according to the block maxima approach [15] and assuming an extreme value Type I distribution with cumulative distribution function

$$
\begin{aligned}
& F(x<X)=\exp \left\{-\exp \left[-\left(\frac{x-\mu}{\sigma}\right)\right]\right\} . \\
& \text { with } \mu \in \square \text { and } \sigma>0
\end{aligned}
$$

Then ,the two distribution's parameters, the location $\mu$ and the scale $\sigma$ are estimated, for each time window and consequently the characteristic value of the climate variable $c_{k}\left(T_{\mathrm{Max}, k} ; T_{\mathrm{Min}, k}\right)$ which is defined as the value values with an annual probability of being exceeded of 0.02 (return period of 50 years) [16], is determined according the following formula

$$
c_{k}=\mu+\sigma\left\{-\ln \left[-\ln \left(1-\frac{1}{50}\right)\right]\right\} .
$$

Finally, in order to assess trends in extremes, factor of change for the distribution's parameter, $\mu$ and $\sigma$, and the characteristic value $c_{k}$ of the investigated climate variables are computed.

Especially for temperatures a delta change factor of change is defined as the difference between the characteristic values at each time window $(t)$ and the corresponding one at the first time window $(t=1)$

$$
\begin{gathered}
F C\left(T_{M a x, k}(t)\right)=T_{M a x, k}(t)-T_{M a x, k}(t=1) . \\
F C\left(T_{M i n, k}(t)\right)=T_{M i n, k}(t)-T_{M i n, k}(t=1) .
\end{gathered}
$$

In Figure 3 and 4 results obtained for one cell (cell \#73) of the considered region are illustrated.

In the graphs, in particular they are reported:

- the results obtained from the analysis of climate model outputs according two different greenhouse gas emission scenarios (red line for CM-RCP45 and blue line for CM-RCP85) with their confidence bands $([5 \% ; 95 \%],[25 \% ; 75 \%])$ obtained from the analysis of the corresponding generated data series;

- the results obtained from the analysis of E-OBS data (green line)

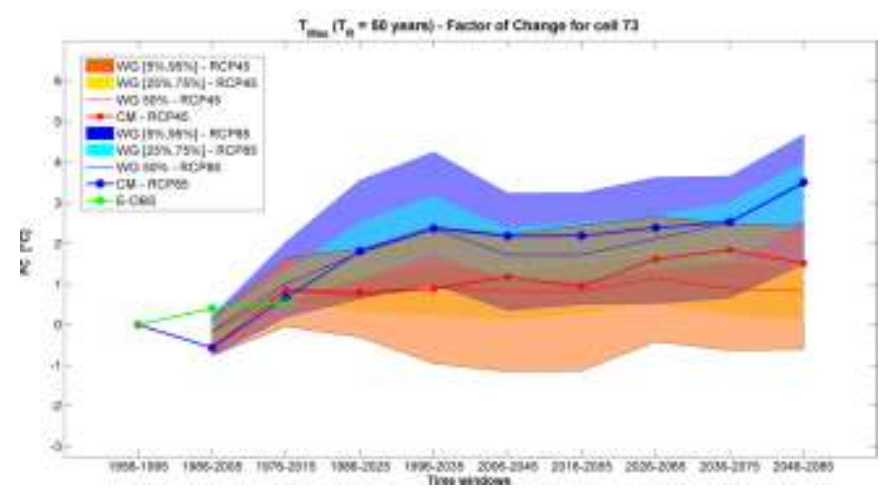

Figure 3. Factor of change for $T_{\mathrm{Max}, k}$ at Cell 73 for two different scenarios, RCP4.5 (red line) and RCP8.5 (blue line), and E-OBS (green line) 
Proc. of the Fifth Intl. Conf. Advances in Civil, Structural and Mechanical Engineering - CSM 2017 Copyright (C) Institute of Research Engineers and Doctors, USA .All rights reserved.

ISBN: 978-1-63248-132-0 doi: 10.15224/ 978-1-63248-132-0-37

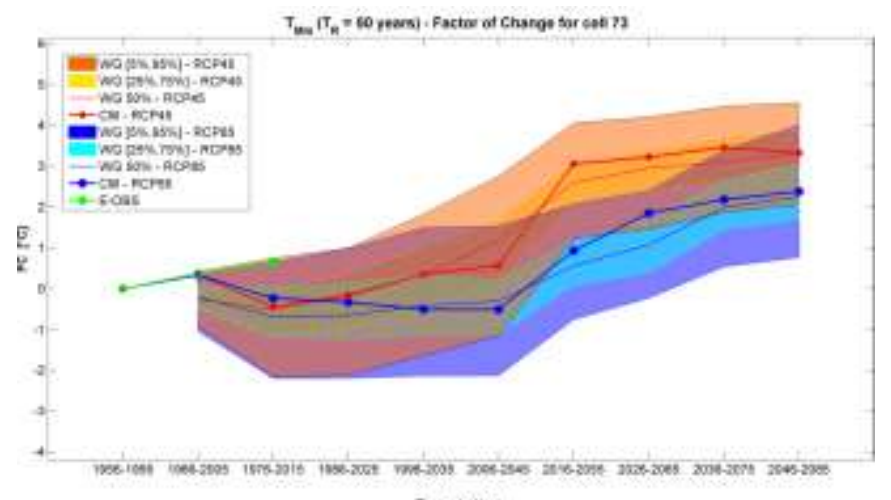

Figure 4. Factor of change for $\mathrm{T}_{\mathrm{Min}, k}$ at Cell 73 for two different scenarios, RCP4.5 (red line) and RCP8.5 (blue line), and E-OBS (green line)

\section{Factor of change maps}

According the results obtained for each cell in the study region, factor of change maps for characteristic values of thermal actions can be drawn taking into account also the uncertainty due to the internal variability of the climate model.

These maps provide a guidance for potential amendments of the current version of minimum and maximum shade air temperature maps in technical standards.

In Figures 5 and 6 factor of change maps for the characteristic values of maximum and minimum temperature $\left(T_{\max , k} ; T_{\min , k}\right)$ are presented in four time windows (19762015, 1996-2035, 2016-2055 and 2035-2075) according the RCP4.5 scenario. In particular, bivariate maps for the $25 \%$ percentile and $75 \%$ percentile of factor of changes are drawn, in order to obtain a more convenient representation of the evolution of extreme temperatures together with their uncertainty.

The results highlight that expectation of increase in extreme temperatures in the near future is characterized by a high confidence level.
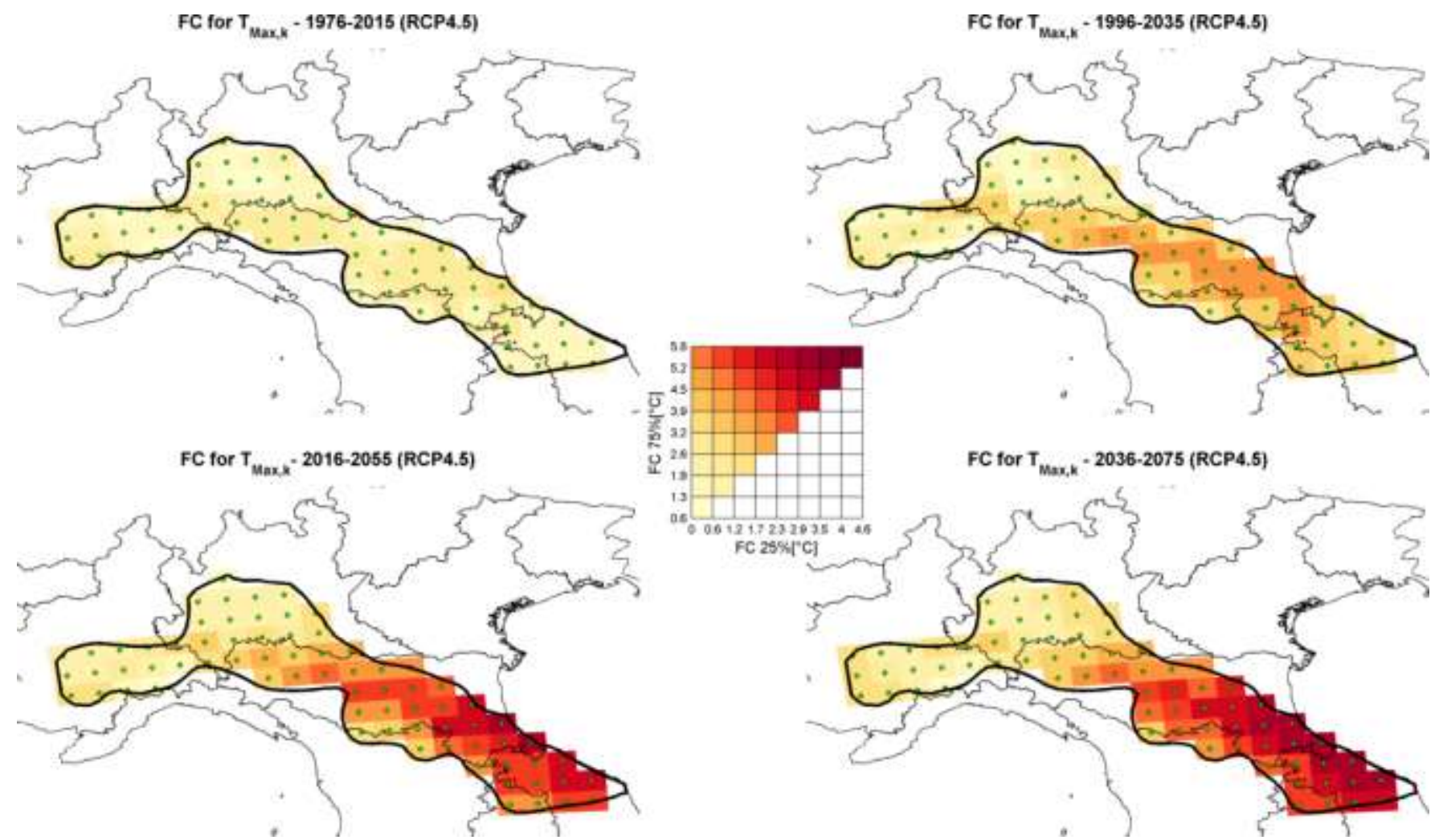

Figure 5. - Factor of Cahnge for $T_{\max , k}-$ Confidence interval [25-75\%] Map (Scenario RCP4.5)

\section{v. Conclusions}

In order to assess the impact of climate change on thermal actions on structures, a new technique for the estimation of future trends starting from the output of climate models has been proposed.

The procedure is implemented through a new weather generator which allows to define consistent climate data series by random sampling from the climate model outputs. Then, analysing the generated series, factor of changes for the characteristic values of maximum and minimum air temperature are derived together with their uncertainty range for the tested climate model and different scenarios. Repeating the analysis for different climate models, it will be possible to take into account also model uncertainty in response to same radiative forcing.

The result show how this technique is very promising and provide guidance for possible amendments of the current version of temperature maps present in structural Codes. In the future works, the analysis will be extended also to different climate variables, obtaining information regarding other climatic actions potentially affected by the impact of climate change. 

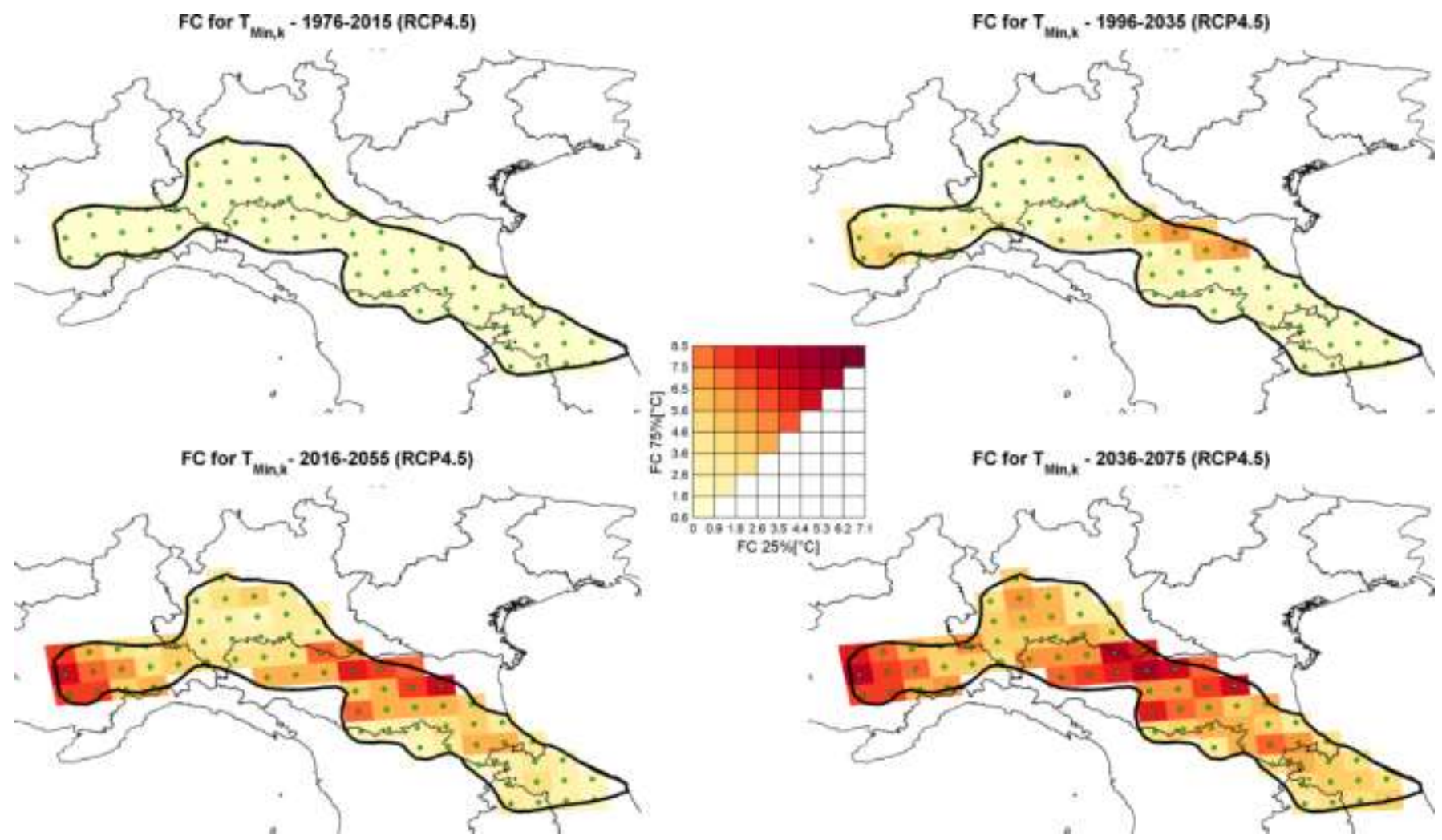

Figure 6. - Factor of Cahnge for $T_{\min , \mathrm{k}}-$ Confidence interval [25-75\%] Map (Scenario RCP4.5)

\section{Acknowledgment}

We acknowledge the World Climate Research Programme's Working Group on Regional Climate, and the Working Group on Coupled Modelling, former coordinating body of CORDEX and responsible panel for CMIP5. We also thank the climate modelling groups (listed in Table I of this paper) for producing and making available their model output. We also acknowledge the Earth System Grid Federation infrastructure an international effort led by the U.S. Department of Energy's Program for Climate Model Diagnosis and Intercomparison, the European Network for Earth System Modelling and other partners in the Global Organisation for Earth System Science Portals (GO-ESSP).

\section{References}

[1] P. Croce, P. Formichi, F. Landi, and F. Marsili, "Estimation of the influence of climate change on snow load on structures", Proc. of 19th IABSE Congress, Stockholm, 2016.

[2] P. Croce, P. Formichi, N. Friedman, F. Landi, and F. Marsili, "Snow Load on Structures under Changing Climate Condition", Proc. of 12th ICOSSAR Conference, Wien, 2017.

[3] IPCC, Managing the Risks of Extreme Events and Disasters to Advance Climate Change Adaptation. Special Report of the Intergovernmental Panel on Climate Change, 2012.

[4] M/515 Mandate for amending existing Eurocodes and extending the scope of structural Eurocode, Brussels, 2012.

[5] CEN/TC250 - Response to Mandate M/515 - Towards a second generation of Eurocodes, CEN-TC250 - N 993, 2013.

[6] L.D. Brekke and J- J. Barsugli, "Uncertainties in Projections of Future Changes in Extremes" in Extremes in a Changing Climate. Detection, Analysis and Uncertainty, Springer ,2012.
[7] IPCC Climate change 2013: the physical science basis. Report by WG1AR5, 2013.

[8] H.J. Fowler et al., "Linking climate change modelling to impacts studies: recent advances in downscaling techniques for hydrological modelling”, Int. J. Climatol. 27: 1547-1578, 2007.

[9] D. Jacob, et al., "EURO-CORDEX: new high resolution climate change projections for European impact research", Reg. Environ Science; Vol.14:563-578, 2014.

[10] D.P Van Vuuren., et al., "The representative concentration pathways: an overview", Climatic Change, Vol.109, 2011.

[11] M.R Haylock., et al., "A European daily high-resolution gridded data set of surface temperature and precipitation for 1950-2006", Journal of Geophysical Research; 113, 2008.

[12] S. Kotlarsky, et al., "Regional Climate Modelling on European Scale: a joint standard evaluation of the EURO-CORDEX ensemble", Geoscientific Model Development; Vol.7: 1297-1333, 2014.

[13] C.G. Kilsby et al., "A daily weather generator for use in climate change studies", Environmental Modelling \& Software 22, 17051719,2007

[14] M.A. Sunyer and H. Madsen, "A comparisono of three weather generators for extreme rainfall simulation in climate change impact studies", Proc. of 8th International Workshop on Precipitation in Urban Areas, 2009.

[15] S. Coles, An Introduction to Statistical Modelling of Extreme Values, Springer-Verlag, London, 2001.

[16] EN 1991-1-5:2003, Eurocode 1: Actions on structures - Part 1-5: General actions - Thermal actions. 